\title{
THE OSMOTIC PRESSURE OF THE AQUEOUS HUMOUR IN EPIDEMIC DROPSY GLAUCOMA
}

BY

\author{
Lieut.-Col. E. O'G. KirWan, M.D., F.R.C.S.I., I.M.S. \\ PROFESSOR OF OPHTHALMOLOGY, MEDICAL COLLEGE, CALCUTTA
}

AN D

S. N. MUKERJEE, M.SC.

UNIVERSITY COLLEGE OF SCIENCE, CALCUTTA

\section{Introduction}

IN a previous paper by one of us (Kirwan, 1934) it was pointed out that epidemic dropsy is the only general disease at present known in which glaucoma forms an integral part and hence is the most important clinical lead we have ever had in the pathogenesis of glaucoma. With a view to the elucidation of the aetiology of primary glaucoma in general, this disease provides a vast field for research, for any advance to gain clearer views of an obscure intraocular condition is valuable.

Investigations into the causation of epidemic dropsy are still being carried out by various workers, but so far without success. Three main theories are at present held: (1) That it is produced by eating rice infected with certain bacteria, (2) That it is an infection which spreads by contact from person to person, (3) That it is due to some deleterious substance which is conveyed through mustard oil.

Different research workers have produced in the past experimental and epidemiological evidence in support of each of these theories. More recently the question of mustard oil being the incriminating factor has received particular attention. The presence of a toxic agent in the plasma of epidemic dropsy cases can now be considered to be established and this toxin produces a general dilatation of the capillaries and an increased permeability of their endothelial walls.

In the glaucoma associated with epidemic dropsy the whole uveal tract shows a marked dilatation of the capillaries without inflammatory changes. The aqueous shows a very marked increase of albumen, whilst the globulins remain the same. All the features theoretically necessary for an abnormal rise in the intra-ocular tension are found present and clinically increased tensions are actually observed.

One of the outstanding signs in this variety of primary glaucoma as pointed out in 1934 is that the anterior chamber, in spite of very high tensions, is seldom shallow and is nearly always 
normal or even deeper than normal. This proves clinically that swelling of the vitreous body cannot be the cause of chronic primary glaucoma, and this fact has evidently been overlooked by Duke-Elder, Davson and Benham in their article on "the swelling pressures of normal and glaucomatous vitreous bodies " (September, 1936) in which they state that up to that date a decisive proof has been lacking.

In this research the osmotic pressures of the aqueous humour in normal eyes and in the glaucoma associated with epidemic dropsy were studied.

The chemical composition of the fluid from the anterior chamber of the eye has been very helpful in determining the origin and the nature of this fluid. Although some workers still hold that the aqueous humour originates as the secretion by the epithelium of the ciliary body of the eye the extensive researches of DukeElder (1937) and his co-workers have established that the composition of the aqueous humour is such that the concentrations of some of the ions present in it are related to those of the same ions in the plasma by a definite thermodynamic relation. Thus the concentrations in normality of sodium and chlorine ions in the two fluids have been shown by him to be related according to the equation :

$$
[\mathrm{Na}]_{\mathrm{Aq}} \times\left[\mathrm{C}^{\prime}\right]_{\mathrm{Aq}}=[\mathrm{Na}]_{\text {plasma }} \times\left[\mathrm{C}^{\prime}\right]_{\text {plasma }}
$$

where $[\mathrm{Na}]_{\mathrm{Aq}}$ and $\left[\mathrm{Cl}^{\prime}\right]_{\mathrm{Aq}}$ represent the concentrations of sodium and chlorine ions respectively in the aqueous humour, $[\mathrm{Na}]_{\text {plasma }}$ and $\left[\mathrm{Cl}^{\prime}\right]_{\text {plasma }}$ represent those in the blood plasma. The concentrations are in terms of normality.

This is obviously the condition characteristic of Donnan's membrane equilibrium, the existence of which is established in this case. These equilibrium considerations led Duke-Elder to the conclusion that the aqueous humour is a dialysate from the blood plasma and that capillary walls and not the capillary endothelium serve as dialysing membranes in such cases. Baurmann (1928) estimated the chemical constituents of an ultra-filtrate of serum and proved that the composition of the anterior chamber fluid is comparable to it. But more recently it has been pointed out by different workers that excepting the ions like $\mathrm{Na}, \mathrm{Cl}^{\prime} \mathrm{K}$, etc., there are a few other constituents whose concentrations in the aqueous humour do not bear out the existence of Donnan equilibrium as is observed in the cases of $\mathrm{Na} \mathrm{Cl}^{\prime}$, etc. 
This, however, at first sight, presents great difficulties in the way of accepting the hypothesis of dialysation. But later researches by different workers have explained the anomalies in the concentration of some of the non-electrolytic substances as due to the metabolic activity within the anterior chamber (especially of the lens). But still there are other constituents, especially ions, whose concentrations continue to offer the same difficulty. DukeElder in $\mathbf{1 9 3 6}$ has modified his older theory of simple dialysis. His present opinion on this point is that "aqueous humour is a dialysate from the blood plasma, showing the ionic distribution characteristic of such a system; superimposed on this simple system is the phenomenon of selective absorption which manifests itself in concentration gradients to certain molecules, but most probably not of $\mathrm{Na}^{+}, \mathrm{K}^{+}$and $\mathrm{Cl}^{\prime} . "$ Thus he is of opinion that having dialysed from the intra-ocular capillaries and before reaching the chambers of the eye, the fluid passes through a physiological membrane, the properties of which maintain a concentration gradient to some molecules and a degree of unidirectional permeability to others ( $c f$. Duke-Elder, 1937).

According to this hypothesis therefore any alteration in the permeability of either the capillary walls or the physiological membrane (mentioned above) or both, will bring about a change in the ionic concentrations in the aqueous humour. The escape of proteins into the aqueous humour will certainly increase the negatively charged micelles in it and as a result of the electrostatic forces the concentration of chlorine ions will tend to decrease and that of $\mathrm{Na}^{+}$ions to increase. A new equilibrium, again obeying the conditions of Donnan's membrane equilibrium but modified by changes in the membrane may be expected in such cases.

In epidemic dropsy the presence in the blood of a histamine-like base has been shown by Chopra and De (1937), which it is believed, brings about an increased permeability of capillaries, as well as a dilatation of these vessels. An increased amount of proteins has also been detected in the aqueous humour of the eye ( $c f$. Kirwan, 1936). But it is not known to what extent the altered permeability affects the process of exudation of fluids and also the osmotic and hydrostatic equilibrium that are normally observed between plasma and this exudate. In the present paper an attempt has been made to ascertain whether in epidemic dropsy the same conditions obtain as in other cases of altered permeability of capillaries or whether the epidemic dropsy toxin brings about the adjustment of equilibrium between blood and aqueous humour in any other way independent of the membrane hypothesis. With this end in view the osmotic pressures of plasma and aqueous humour as well as their chlorine ion concentrations were determined and compared with those of normal subjects. 


\section{Experimental Portion}

Specimens of 0.25 c.c. of aqueous humour from epidemic dropsy glaucomatous eyes were obtained from the Eye Infirmary, Medical College Hospitals, Calcutta. Blood sera of the same patients were also obtained. The fluid from the anterior chamber of the normal eyes was all obtained from aphakic eyes. The osmotic pressure was calculated from determinations of the relative lowering of vapour pressure by the thermo-electric method as suggested by Hill (1930) with slight modifications introduced by Baldes (1934). A galvanometer of the order of $10^{-11}$ was used and the scale was placed at a distance of about 10 metres from it, wherein the reflections were noted. The solutions to be tested were compared with 0.85 per cent. $\mathrm{NaCl}$ in every case after keeping both these fluids on the thermo-electric junctions at constant humidity for twenty minutes for the establishment of the equilibrium. It may be mentioned here that a 0.75 per cent. saline when balanced against a 0.85 per cent. saline always showed a deflection of $80(+2) \mathrm{mm}$. on the scale. The osmotic pressures of plasma and aqueous humour have been calculated on the assumption that these fluids contain an equivalent amount of pure sodium chloride. Such an assumption can be justified in view of the minute quantities of other substances present in comparison with the preponderating amount of sodium chloride. The osmotic pressure of 0.85 per cent. saline was calculated to be $5,775 \mathrm{~mm}$. of mercury from its data on the degree of electrolytic dissociation (vide Landolt-Bornstein Tabellen). The results have been tabulated below :-

TABLE I

(Normal Patients)

\begin{tabular}{c|c|c|c}
\hline \multirow{2}{*}{ No. } & \multicolumn{2}{|c}{ Osmotic Pressure in mm. Hg } \\
\cline { 2 - 4 } & Serum & Aqueous humour & Difference \\
\hline 1 & 5873 & 5843 & 30 \\
2 & 5881 & 5853 & 28 \\
3 & 5881 & 5855 & 26 \\
4 & 5937 & 5909 & 28 \\
5 & 5901 & 5873 & 28 \\
6 & 5894 & 5869 & 25 \\
7 & 5850 & 5821 & 29 \\
\hline & & & 28 \\
\hline
\end{tabular}


TABLE II

(Glaucoma Patients)

\begin{tabular}{r|c|c|c|c}
\hline \multirow{2}{*}{ No. } & \multicolumn{2}{|c|}{ Osmotic Pressure in mm. Hg } & $\begin{array}{c}\text { Intra-ocular } \\
\text { tension in } \\
\text { mm. Hg }\end{array}$ \\
\cline { 2 - 5 } & Serum & Aqueous Humour & Difference & \\
\hline 1 & 5866 & 5857 & 9 & 36 \\
2 & 5915 & 5901 & 14 & 40 \\
3 & 5880 & 5859 & 21 & 36 \\
4 & 5730 & 5715 & 15 & 50 \\
5 & 5895 & 5874 & 21 & 36 \\
6 & 5940 & 5918 & 22 & 38 \\
7 & 5850 & 5831 & 19 & 40 \\
8 & 5724 & 5704 & 20 & 40 \\
9 & 5850 & 5838 & 12 & 56 \\
10 & 5810 & 5795 & 15 & 57 \\
11 & 5785 & 5771 & 14 & 70 \\
\hline Average & 5840 & 5824 & 16 & 45 \\
\hline
\end{tabular}

TABLE III

(Showing the average chlorine ion concentrations)

\begin{tabular}{l|c|c}
\hline \multirow{2}{*}{\begin{tabular}{l} 
Nature of cases \\
\cline { 2 - 3 }
\end{tabular}} & $\begin{array}{c}\text { Concentration of chlorine ions in } \\
\text { gms. per 100 c.c. of } \\
\text { serum }\end{array}$ & $\begin{array}{c}\text { gms. per 100 c.c. of } \\
\text { aqueous humour }\end{array}$ \\
\hline $\begin{array}{l}\text { Normal } \\
\text { Epidemic dropsy - }\end{array}$ & $0.3664(1)$ & $0.4435(2)$ \\
\hline
\end{tabular}

(1) Vide Duke-Elder (1934).

(2) Findings of Mestrezat and Magitot (1921).

\section{Discussion}

Since the diffusible ions are unequally distributed a difference in osmotic pressure must exist between a dialysate and its parent fluid. A difference is obtained in fact, and Duke-Elder has shown that the osmotic pressure of the intra-ocular fluid corresponds exactly with that of a dialysate of the capillary blood in the normal state of the eye. In epidemic dropsy glaucoma the osmotic pressure difference is much less as compared to normal cases. The increase 
of proteins in the aqueous humour and a consequent reshuffling of the diffusible ions make the aqueous humour more of a plasmoid type and the difference in the osmotic pressures is adjusted accordingly.

The osmotic pressure difference is always related to the intraocular pressure under equilibrium conditions by the relation that the blood pressure in capillary circulation exceeds the intra-ocular pressure. This amount is equal to the difference between the osmotic pressure of the two fluids. In other words, equilibrium is attained when the pressure of flow of fluid from the blood to the anterior chamber is exactly balanced by an opposite pressure from the intra-ocular fluid to the blood.

The diminution in the osmotic pressure difference between serum and aqueous humour (Table II) seems to be interesting in the light of these considerations. It evidently indicates that the difference between the capillary pressure and the intra-ocular pressure must also be as low. This, however, may be brought about in either of two ways :-Firstly, by a diminution of the first factor, viz., the pressure of the blood flow in the capillary, secondly by an increase in the intra-ocular tension. The dilatation of the blood tissues in the sub-epithelial connective tissues of the ciliary processes and the enormous dilatation of the capillaries of the choroid, as observed by Kirwan (1936), should certainly decrease the pressure of blood to a certain extent, but from observations on the blood pressure of epidemic dropsy patients it seems unlikely that it can account for the difference of pressure so low as that between the osmotic pressures of serum and aqueous humour. A low osmotic pressure difference between these two fluids, therefore, indicates that the intra-ocular pressure must rise considerably to bring about such a low value. Such abnormal rise of intra-ocular tension has been actually observed in all cases of epidemic dropsy glaucoma, and in fact a pressure about $50 \mathrm{~mm}$. $\mathrm{Hg}$ is characteristic in these cases (Kirwan, 1936).

Regarding the origin of these increases of pressure it may be said that the alteration of the filtration angle of the eye does not appear to play an important rôle in this case, since Kirwan (1936) has observed that the channels of absorption in the eye, viz., the canal of Schlemm and tissues round it do not show any abnormalities either in cellularity or increased fibrosis. Thus it appears that the rise in the intra-ocular tension may not be the primary outcome of any decrease in the normal rate of drainage but rather of an accumulation due to increased inflow which the outlets cannot cope with.

The tension, therefore, owes its origin probably to a greater inflow of fluids than can be normally drained out. The albuminoid composition of the fluid in glaucoma cases obtained in epidemic 
dropsy increases the osmotic pressure of the aqueous with a simultaneous diminution on the plasma side. The outflow of plasma into the aqueous is thus promoted and more and more fluids pass out from the blood till at last a back pressure is developed in the anterior chamber sufficient to prevent any further flow. The entire phenomenon thus seems to be due to the disappearance of proteins from the serum and their appearance in the aqueous due to an alteration of capillary permeability.

It will not be out of place here to discuss the effect of the change in permeability of capillaries. The escape of proteins raises the question : whether the change in permeability alters the nature of the filtration process, or, whether the same dialysation process governed by laws of Donnan's membrane equilibrium still operates as in normal subjects. The concentration of chlorine ions in blood serum and aqueous humour both in normal and epidemic dropsy subjects as given in Table III gives us a qualitative idea. According to Donnan's membrane hypothesis a higher chlorine ion concentration is expected under normal conditions in the aqueous humour than in the serum. That this is true is evident from Table III. If the membrane hypothesis holds in epidemic dropsy cases also there should be a small diminution of chlorine ion concentration in aqueous humour while that of serum should slightly increase. Such changes, however, do occur, as evident from Table III. It may, therefore, be inferred from these observations that change in the permeability of capillaries that occurs in epidemic dropsy does not alter the nature of the process of exudation of fluids from blood, but sets it at an altered state of equilibrium.

\section{Summary and Conclusions}

1. In epidemic dropsy glaucoma the difference between the osmotic pressure of blood serum and the aqueous humour is considerably reduced as a result of the appearance of proteins in the latter.

2. In consequence a reshuffling of ions takes place exactly in the same direction as predicted by the hypothesis of membrane equilibrium. The concentration of chlorine ions diminishes in the aqueous humour while an increase can be observed in the serum.

3 . The evidence tends to support the view that in epidemic dropsy glaucoma the filtration of fluid into the anterior chamber takes place by the process of dialysation as usual, but that the equilibria concerned are at a level different from that of normal subjects, due probably to the altered permeability of the dialysing membrane.

We are indebted to Brevet-Colonel R. N. Chopra, C.I.E., K.H.P., I.M.S., Director of the Tropical School of Medicine, 
Calcutta, for his valuable co-operation, help and advice in carrying out this piece of research. We also tender our grateful thanks to Dr. P. K. Biswas, of the Eye Infirmary, Medical College Hospitals, Calcutta, for many services.

\title{
REPERENCES
}

BALDES, E. T. (1934)-Journal Scientific Instruments, Vol. XI, July.

Baurman N. (1928)-Ber. Ophthal. Ges., Heidelberg, Vol. XLVII, pp. 157-221.

Chopra, R. N., and DE. N. (1937)-Indian Jl. Med. Research, Vol. XXV, p. 101. Duke-Elder, W. S., Davson and BenhaM. (1936)-Brit. Jl. of Ophthal., Vol. XX. p. 520.

DUKE-ELDER, W. S. (1927)-Biochem. Jl., Vol. XXI, p. 66.

- (1934)-Physiol. Rev., Vol. XIV.

(1936)-Biochem. Jl., Vol. XXX, p. 773.

- (1937)-Brit. Jl. of Ophthal., Vol. XXI, p. 377.

Hill, A. V. (1930)-Proc. Roy. Soc., Series A, Vol. CXXVII, p. 9.

KIRWAN, E.O'G. (1934)-Arch. of Ophthal., Vol. XII, July.

(1936)-Brit. Jl. of Ophthal.. June, p. 321.

Mestrezat and Magitot. (1921)-Comp. rend. Soc. Biol., Vol. LXXXIV, p. 185.

\section{STUDIES ON THE PATHOGENY OF TRACHOMA*}

\author{
BY \\ L. A. Julianelle \\ OSCAR JOHNSON.INSTITUTE WASHINGTON UNIVERSITY SCHOOL \\ OF MEDICINE, ST. LOUIS, MISSOURI
}

DURING the course of studies pursued in this laboratory for the past six years on the aetiological relationships of trachoma, certain facts have been revealed which reflect the nature of the causative agent of this disease. It appears desirable at this time to bring together these facts in the manner of a recapitulation in order to construct a pattern of the pathogeny of trachoma.

In the work conducted thus far, it has been demonstrated, as others showed before us $^{1}$, that material derived from the conjunctiva of patients with trachoma, while completely innocuous for dogs, rabbits, hogs, guinea-pigs, rats, and mice, induces on the conjunctiva of monkeys an infection characterised essentially by folliculosis ${ }^{2}$. Preceded by an incubation period of several days to a month, the experimental disease frequently extends from the inoculated to the uninoculated eye and endures for a few weeks to many months, in some instances two and three years. The histological changes, although simulating those in trachoma, are

* Read at the XV International Congress of Ophthalmology, Cairo, December 10, 1937. Conducted under a grant from the Commonwealth Fund of New York. 